\title{
La unidad de inteligencia y realidad en la metafísica de X. Zubiri
}

\section{Introducción}

"En la intelección me 'está' presente algo de lo que yo 'estoy' dándome cuenta. La unidad indivisa de estos dos momentos consiste, pues, en el 'estar'. El 'estar' es un carácter físico y no solamente intencional de la intelección" (IRE 22)

"La unidad de este acto de 'estar' en tanto que acto es lo que constituye la aprehensión... la aprehensión es el acto presentante y consciente. Esta ' $y$ ' es justo la esencia misma unitaria y física de la aprehensión. Inteligir algo es aprehender intelectivamente este algo". (IRE 23)

"El acto propio y formal de la intelección respecto a lo inteligido es ser mera 'actualización' de la cosa inteligida, y por tanto lo inteligido en cuanto inteligido es tan sólo 'actualizado'."(SE II3)

Estos textos me parecen suficientemente claros para plantear el tema INTELIGENCIA y REALIDAD.

En una expresión muy cara para Zubiri dirá (NHD 276)' : 'todo depende del sentido que le demos a esa $\chi^{\prime}$ '. $O$ si se quiere mejor, el tipo de unidad que sea capaz de soportar la ' $y$ ' dará la comprensión de qué sea, tanto Inteligencia, como Realidad. $O$ dicho todavía de otra manera, ¿hay algún fundamento desde el que Inteligencia y Realidad se descubran como objeto de saber? $O$ finalmente, qué hay de inteligible en la Realidad y qué de real en la Inteligencia, lo cual sabido, pueda ser dicho como lo verdadero de lo real. Se trata en definitiva, de la congenereidad entre Inteligencia y Realidad. Es meter en la vía del sin sentido la prioridad de la inteligencia sobre la realidad, o de ésta sobre aquélla.

Conviene desde un comienzo poner de manifiesto que tanto Inteligencia como Realidad aparecen en las dos obras — "Sobre la Esencia", y "Inteligencia 
Sentiente"-, como términos cuyo contenido conceptual pugna por aclarar, cuál sea el momento donde la Realidad se actualiza como siendo inteligible.

El presente estudio está realizado sobre las dos grandes obras de Xavier Zubiri, 'Inteligencia y Realidad' (IRE, IL, IRA) (Alianza Ed., Madrid, 1980-82, 'Sobre la Esencia' (SE) Sociedad de Estudios y Publicaciones. Madrid, 1962Alianza Ed.5². 1985 )

En forma de tesis, podría formularse: si la inteligencia es actualización de formalidad de realidad, el objeto del saber primario es el qué de la realidad. Ahora el qué responde al contenido de esa ' $y$ ', y no es otro que la conclusión a la que llega Zubiri al final de la Sobre la Esencia: "En definitiva (como principio), la esencia es principio estructural de la sustantividad."

El desarrollo completo de esta tesis supone proceder primero por aproximaciones sucesivas. $Y$ una segunda parte, en la que la unidad de - Inteligencia y Realidad-, se exprese como saber primario o principial de la realidad en la obra de 'Sobre la Esencia'.

\section{Primera aproximación: Esa ' $Y$ ' es IMPRESIÓN}

Lo más elemental desde un análisis que parta de la inteligencia es considerar a ésta como 'la mera actualización impresiva de lo real como real'. (IRE 189).

Impresión es lo formalmente constitutivo del sentir (IRE 31).

La estructura (IRE 92) de la impresión tiene tres momentos: afección, alteridad, fuerza de imposición. La unidad de esos tres momentos constituye la impresión. La aprehensión de la tal impresión, por su momento de alteridad, determina la inteligencia, y a su vez, el momento de fuerza de imposición determina la realidad.

El momento de afección sitúa lo impresivo en la aprehensión. Esta unidad estructural determina el proceso del sentir: proceso que se estructura como suscitación, modificación tónica y respuesta (IRE 39).

(El momento de alteridad) - lo otro en cuanto otro-, -la nota-, tiene un modo de quedar. El contenido queda, - esta autonomía es un momento decisivo (IRE 35)_- Es el momento de formalidad, formalidad que es mera descripción de esta autonomía. Esta formalidad es término de una habitud. La habitud es el modo de haberse con las cosas el sentiente, de ahí que determine en parte el contenido. La nota queda en una forma determinada según la habitud: este modo en cuanto determinado por la habitud es formalización (IRE 36).

La modalización de la alteridad es la unidad estructural de contenido y formalidad.

La formalización constituye la 'unidad' del contenido sentido(IRE 37). Esta modalización de formalización depende en última instancia de la unidad de independencia de una constelación de notas (percepción), (IRE 38). 
La exigencia de esta unidad dará pie al estado constructor como plasmación definitiva de la unidad de realidad.

En conclusión, la unidad estructural de la alteridad depende de la índole del animal. Y ello va a determinar la inteligencia sentiente (como acto). La ' $y$ ' es estructura, o mejor, unidad estructural. La fuerza de imposición de esta unidad (autonomía más o menos del contenido que queda), desencadena el proceso del sentir... intelectivo en el hombre.

Así la formalización es autonomización, por el modo de quedar. Frente a las ideas de información y configuración de Kant y la Gestalt respectivamente.

Los modos de formalización (en un análisis modal de la formalización), son dos fundamentalmente:

La estimulidad. Su expresión, el signo, es la formalidad de alteridad del mero estímulo-respuesta (IRE 51). Su fuerza de imposición es objetividad: signo objetivo de respuesta.

Objetividad viene a ser la mera alteridad signitiva en cuanto se impone al aprehensor (IRE 52)

La realidad: la nota o unidad de notas no queda sólo como signo de respuesta, sino en propio, - grado de autonomía que comporta el 'de suyo' como un quedar presente como tal-. Eh ahí la aprehensión de realidad, de la realidad como formalidad.(IRE 57)

Este 'quedar presente' tiene un nombre muy preciso en la filosofía de Zubiri, es actualidad. De ahí que podamos decir que la ' $y$ ' de Inteligencia y Realidad sea actualidad. Esta actualidad lo es de una forma de presentidad, de un modo de estar como en propio de algo que (es) de suyo.

Como esta formalidad del de suyo modela los tres momentos de la impresión, empieza ello a empistarnos en la estructura de la ' $y$ ':

$>$ El momento de afección queda 'afectado' por el 'se'.

$>$ El momento de alteridad queda como un suyo que es 'prius'.

$>$ El momento de fuerza de imposición es toda la fuerza de la realidad.

La unidad de estos tres momentos es la unidad del acto aprehensor. Es un estar, no algo noético-noemático, es algo érgico. No-ergia sería la expresión (IRE 64). Este estar presente en cuanto estar es la esencia de esa 'actualidad'.

Y la Impresión es la esencia de la unidad estructural de la ' $y$ ' de Inteligencia y Realidad. Dicho de otra manera, la ' $y$ ' como impresión es instalación en lo real (aquí está el orto de la aprehensión primordial de realidad).(IRE 65)

Vamos a describir "en cascada" todo lo que puede dar de sí la conceptualización de la 'y' como impresión. 
La ' $y$ ' es un prius, y por ello (fuerza de imposición) es realidad.

La ' $y$ ' como estructura impresiva, es el momento de afección que se va determinando por el momento de alteridad, que se impone con la fuerza del 'suyo' del de suyo.

La unidad de signitividad se rompe y deja paso al «en propion: es el momento 'hiper' de la formalización,(IRE 71). Ello constituye el principio estructural del animal no humano y humano.

La ' $y$ ' no es unidad de sentir y ser, como acto y acto (filosofía clásica, IRE 80.). Ni sentir más inteligir como unidad de acto (Kant). La ' $y$ ' está en función del 'en' (los sentidos sienten en la inteligencia) y no del 'a'.(IRE 83):

"...el modo mismo de inteligir es sentir realidad".

La ' $y$ ' como fundamento de objetos de la inteligencia sentiente. (IRE 86)

El despliegue de la ' $y$ ' es conceptuar desde inteligencia sentiente. (IRE 87). Este despliegue tiene dos fases:

1. Análisis de hechos: acciones y habitudes tomadas por sí mismas.

2. Conceptuación estructural de las mismas. (IRE 95)

La ' $y$ ' como despliegue en estructuras de sentir e inteligir, determina la habitud de intelección sentiente, cuyo acto formal es la impresión de realidad. (IRE 96).

El ámbito de la ' $y$ ': la unidad estructural de inteligencia y sentir es determinante de la habitud de intelección sentiente. (IRE 96)

La ' $y$ ' como impresión de realidad se estructura en modos de sentir intelectivo y de intelección sentiente, cuya unidad es estructural, es primordio de constructo: los modos se recubren, modos-de. (IRE 109)

Así la ' $y$ ' como impresión es unidad de realidad:

"La inteligencia sentiente es la estructuración de la diversidad de sentires en la unidad intelectiva de realidad". (IRE 111)

Esta estructura de la ' $y$ ' es de carácter transcendental. Ello es un 'más'. (IRE 115). Este 'más' es comunicación en un ex- de un in- (mismidad). De ahí sus cuatro momentos: apertura, respectividad, suidad, mundanidad. (IRE 121) 122)

En apretada síntesis, la ' $y$ ' es una ex-pansión de una ex-tensión. (IRE

La estructura de la impresión de realidad es la estructura de la intelección sentiente. (IRE 124)

La ' $y$ ' es función talificante y transcendental. Estas funciones constituyen como tales la unidad estructural de la impresión de realidad. (IRE 125) 
La esencia de esta ' $y$ ' es presentidad (IRE 135), como un estar: Desde inteligencia sentiente es mera actualidad. (IRE 136)

Como actualidad, es mero estar desde sí misma: ' $y$ ' es formalidad de realidad: reidad. 139)

Estar presente desde sí mismo por ser real: esencia de la actualidad. (IRE

Esta actualidad de lo real en la intelección, considerada desde la intelección, tiene un carácter preciso es «la verdad real»: estamos ante la $2^{\mathrm{B}}$ Aproximación.

\section{Segunda aproximación: Esa ' $Y$ ' es VERDAD REAL}

Verdad es un momento en la intelección: actualidad - $y$ - añadir (esto es una dimensionalidad) la mera actualización intelectiva. (Para ser rigurosos, intelectiva es un carácter de la actualización).

Realidad y verdad son aspectos de actualización. La 'y', unidad estructural: una dimensión, la verdad. La ' $y$ ', unidad estructural. Está claro que no toda realidad tiene verdad (IRE 230), ni realidad y verdad son correlativas. El 'en' verdad en forma de ratificación, verdad real. Su fundamento es respectividad.

Desde esta verdad se puede apreciar la estructuralidad de la ' $y$ ': desde la realidad...: totalidad, coherencia, duratividad.

La ratificación de cada dimensión es a su vez una dimensión de la verdad. La totalidad, en riqueza de lo aprehendido. La coherencia, en el qué. La duratividad, en estabilidad (ratificación del estar siendo, IRE 240).

Esta ratificación que se modaliza a su vez: la manifestación (en SE 127: patentización), la firmeza, la constatación (IRE, 241).

En fórmula que resume las dos aproximaciones hasta ahora vistas de la ' $y$ ':

"La inteligencia sentiente está esencialmente constituida por impresión de realidad. En cuanto impresiva, esta intelección es sentiente. En cuanto siento lo otro como alteridad de 'en propio', de 'de suyo', este sentir es intelectivo. En cuanto la realidad aprehendida está ratificada en la impresión misma, es verdad real. La ratificación es la fuerza de imposición de la impresión de realidad. La ratificación es la fuerza de la realidad en la intelección."(IRE 241)

En definitiva esta ' $y$ ' es arrastre: la estructura formal de la intelección sentiente. (IRE 242; SE 127)

Forma y modo de la intelección primaria:

El inteligir es la esencia del entender (despliegue de estructuras de lo real), y no al revés, (IRE 249). 
La fuerza de la inteligencia es fuerza de aprehensión de realidad, no de entender. La inteligencia al ser realidad, encierra a la vez en sí el objeto de la intelección y la índole estructural del acto mismo de inteligir: versión de la aprehensión a lo real. De ahí la $3^{3}$ aproximación de la 'y' como respectividad.

\section{Tercera aproximación: La 'y' es RESPECTIVIDAD (IRE 250) [el desde]}

Esa especie de versión de la aprehensión a lo real es lo constitutivo de la aprehensión como realidad. Es el momento de respectividad:

“...la intelección misma consiste formalmente en ser aprehensión de lo real como real. De ahí que la unidad de inteligencia y realidad no sea una 'relación', sino mera 'respectividad': es el 'estar' aprehensivamente en la realidad."(IRE 250)

"La respectividad ...es un momento... de la formalidad misma de realidad en cuanto tal."(IRE 120)"

\section{Respectividad del estar. Este estar tiene tres momentos:}

El estar inteligido: sentible. Estar actualizando lo aprehendido: mera actualización. Instalación (fugaz, una cosa, otra, otra....): pero la realidad reifica.

Esta 'realidad' de impresión de realidad, es trascendentalmente abierta. La articulación de cosa real y realidad (fuerza de imposición) es trascendentalidad.

Esta ' $y$ ' de Inteligencia y Realidad, es la unidad estructural de Inteligencia sentiente:

"La unidad intrínseca y formal de aquellos tres momentos (sentir lo real, mera actualización, instalación) es lo que constituye la inteligencia sentiente. La realidad sentible es aprehendida en inteligencia sentiente, y su aprehensión es una mera actualización que nos instala aprehensivamente en la realidad. Estamos instalados en la realidad por el sentir, y por esto sentir lo real es estar ya inteligiendo." (IRE 252)

Esta realidad trascendentalmente aprehendida está modalizada: son los modos de actualización.

La actualidad intelectiva queda afectada por la respectividad de lo real mismo. Y esa afección son los modos de intelección: el 'en realidad' (IRE 254) es una modulación del 'como (modo primordial) realidad' (IRE 255). El modo de realidad es el 'hacia'.

Impresión de realidad e impresión primordial de realidad: distinción modal, como modalización (la unidad está en el 'en' y 'por sí mismo'), solamente (fijación, aunque sea dentro de un sistema). ' $Y$ '= de realidad (IRE 258). 
Ante ese solamente ¿cuál es el acto intelectivo y su índole? :

La fijación en cuanto acto modal es atención.

Intelección atentiva: concentración-precisión. El resto es marginación.

La índole de los modos de intelección penden de la índole de los modos de realidad: Quedar (realidad)-‘requedar’, retención, retinencia (admite grados: absorción).

La ulterioridad, o los modos ulteriores de actualización constituyen el sistema de la ' $y$ ' entre Inteligencia-Realidad.(IRE 269)

\section{Cuarta aproximación: La ' $y$ ' es RE-ACTUALIZACION} (el en)

Las nociones de Campo y Mundo van a ser definitivas para la comprensión de esta $4^{\mathrm{a}}$ aproximación.

Campo de realidad constituido por la respectividad de suidades

Mundo constituido por la unidad de (respectividad) 'la' realidad.

Son dos dimensiones de una misma respectividad, de ahí que yo las sitúe en la actualización: una respectividad, dos actualizaciones, o sea momentos:

"Respectividad campal y respectividad mundanal no son ciertamente dos respectividades, pero sí son dos dimensiones distintas de la respectividad de lo real en cuanto tal... El campo de realidad no es un orden de cosas extrínseco a la realidad de ellas. Por el contrario, es un momento intrínseco a cada cosa, un momento campal suyo. Aunque no hubiera más que una sola cosa real, esta cosa sería ya campal. Toda cosa real tiene,... un momento de contenido y un momento de formalidad. Sólo por el segundo momento es por el que las cosas constituyen un campo de cosas reales. Como el momento de realidad de las cosas nos lo dan las cosas mismas en impresión de realidad, resulta que el campo de realidad está determinado por las cosas reales mismas y no sólo por la unidad de mi acto perceptivo." (IRE 270)

Lo cíclico (respectividad) es típico del campo:

"Entre una cosa real y el campo de realidad hay una respectividad rigurosamente cíclica" (IRE, 270).

Como concepto forma parte esencial del saber científico (IRE 271). Distancia es un momento del campo de realidad y no al revés.

El momento mundanal es de la realidad, no confundir con el momento campal que sólo lo es transcendental. Al ser dos dimensiones de la trascendentalidad resulta que "el campo no es sino el mundo en cuanto momento sentido de la suidad" (IRE 272). [El ejemplo de la realidad humana, IRE 273-4]. 
Ahora estas actualizaciones determinan modalizaciones intelectivas. Eh ahí la ' $y$ ' como actualización hacia la inteligencia desde la realidad: Re-Actualización, último paso de las aproximaciones de la ' $y$ ':

Logos, la intelección de la realidad campal (en realidad):

Intelige en procedencia - fundado en - hacia lo que (movimiento) (re-versión) [IRE 275]. Re-enriquece el contenido de la aprehensión primordial.

La razón es marcha hacia el mundo, marcha transcendental: de ahi que la razón 'fabrica' objetos, en el sentido de la objetualización del como de 'como realidad'.

\section{Visión de 'SOBRE LA ESENCIA' desde LA UNIDAD DE INTELIGEN- CIA Y REALIDAD}

Nota preliminar: Este comentario a cerca de la obra de "Sobre la Esencia", intenta captar aquellos puntos de transparencia donde un análisis de la realidad -actualizada en la impresión, al dar de sí como respectiva, se reactualiza como principio de su propia estructura sustantiva. (El análisis irá poco a poco poniendo 'luz' y rigor en el entramado de esta formulación).

Dice Zubiri en 'Inteligencia y Razón': “Todo lo real es un sistema constructo de notas que lo constituyen, y que por eso llamo constituyentes. Pero entre estas notas hay algunas que no están fundadas en otras del sistema mismo. Y estas notas son entonces más que constituyentes, son constitutivas, y lo que constituyen es la esencia de la cosa real. Su unidad es en efecto, unidad coherencial primaria. Pues bien, amplitud es la diferencia entre las constituyentes y las notas constitutivas en orden a la fundamentación de lo real en profundidad. Y esto es muy complejo. Porque la esencia es lo que constituye como realidad a la cosa real de la que es esencia". (IRA 115).

Sólo un paciente análisis del concepto de esencia nos pondrá de manifiesto la inteligibilidad de la expresión zubiriana: "la esencia es lo que constituye como realidad a la cosa real de la que es esencia."

\subsection{La Vía Conceptiva, i Es Inevitable?}

"Al hilo de la transformación del concepto de realidad como sustancia, ha ido transformándose el concepto de 'lo que' es esta realidad, a saber la esencia. Por singular paradoja, pues, nos hallamos ante el mismo problema con el que desde un principio tuvo que debatirse el propio Aristóteles: la implicación entre la estructura radical de la realidad y la índole de su esencia". (SE 5)

Porque la esencia es un momento de la sustantividad, i.d. de la realidad.

La esencia es algo real, de ahí la posibilidad de una filosofía de la esencia como momento del 'qué'. 
Las notas son algo físico, los aspectos algo intencional, lógico, o conceptivo. (véase SE 9-12)

Para Zubiri, la unidad es el punto de comprensión de toda realidad. Correlación comprensiva: unidad - 'la'- - " en definitiva (ver SE 18), la pregunta por la esencia misma, es la pregunta por la unidad principial de la cosa real'. Unidad primaria necesitante de la cosa real (ver SE 23).

Esta unidad principial necesitante constituye el «no» fundamental a las conceptuaciones diversas de la esencia.

Como de alguna manera quien va directamente a esa unidad como unidad eidética de sentido, es Husserl, por ahí va a comenzar Zubiri su dialéctica..

Al hilo de la postura de Husseri, va Zubiri explicitando conceptualizaciones propias, que serán claves para el desarrollo de su tesis.

Haciendo alusiones a la conciencia cartesiana, - tema fundamental en el inicio de IRE-, nos dice:

"No puede hablarse de 'la' conciencia por la sencilla razón de que la conciencia carece de toda sustantividad, de todo ser sustantivo... hay actos conscientes pero no hay 'conciencia'... Por eso el problema radical no está en el momento de conciencia, sino en la índole 'física' de aquellos actos."(SE. 29)

La índole formal de la conciencia es actualizar.

Las esencias son 'de' la cosa (primordio de construcción). Para Zubiri la esencia no es algo dado, hay que inquirirla:

“En la medida en que la esencia está realizada 'en' la cosa, es 'de' ella. Toda esencia es, por su propio ser, esencia 'de' la cosa, un momento de ella". (SE 30)

Así pues, no hay esencia sino esencia de la cosa real:

"Al separar esos dos momentos —esencialidad y facticidad-y sustantivarlos a beneficio de dos tipos de saber - saber absoluto y saber empírico- Husserl ha descoyuntado la realidad, y la realidad se le ha ido para siempre de las manos."(SE. 32)

Si la esencia es algo intrínseco a la cosa. Lo esencial de la cosa vendrá expresado en su verdad. Esta (la verdad) se irá determinando como verdad real. Ahora bien, surge al paso el concepto de verdad ontológica como la verdad de la cosa expresada en su concepto:

La exposición de la esencia como concepto formal y como concepto objetivo, le va dando pie a Zubiri para seguir determinando su idea de esencia. Vamos a seguirlo detenidamente. 
Postura de Zubiri ante la razón, consecuente con su distinta concepción de la inteligencia, —en contraste con Hegel-:

“.....No existe eso que Hegel llama 'la' razón, sólo existen razones intrínsecamente distintas."(SE. 47)

La verdad dual de Zubiri cōmo expresión del Logos. Notemos cómo va persiguiendo su concepto de verdad real. A partir de - SE 113-, empezará a explicitarlo en toda su determinación y alcance.

Ante la supositalidad hegeliana cuya índole intema consiste en ser automoción (concepto de devenir), Zubiri va a contraponer lo que es para él el momento determinante de la realidad, el 'prius':

“....Nada se gana con subrayar el momento del autós sino todo lo contrario. Porque, ¿qué se entiende por autós? Es autós, es 'sí mismo', una cosa real que posee un carácter de 'mismidad' física, en virtud del cual 'se mueve' a sí mismo. Aquí el autós, la realidad que es 'misma', es un prius respecto de su 'automoción', es un principio. A fuer de tal, está allende el movimiento."(SE 55).

Como conclusión a la crítica de la postura de la Hegel, nos descubre Zubiri el fondo estructural de Inteligencia y Realidad en aquella primera aproximación que es la impresión de realidad:

“Al sumergirse en la pura intelección por sí misma, la razón para Hegel sólo se ocupa de sí misma y se ocupa de ella no en cuanto realidad sino en cuanto inteligente, su modo mismo de ocupación es también puramente intelectivo. A pesar de su presunto devenir, la razón en Hegel no hace sino concebirse a sí misma...Una cosa son, pues, los conceptos formales, otra la realidad." (SE 58)

Los interlocutores de la esencia como concepto objetivo son fundamentalmente Descartes, Leibniz y Kant.

Zubiri, al hilo de su exposición, sigue explicitando la conceptualización de aquellos términos que van a volver inteligible su noción de esencia.

Como planteamiento específico respecto al concepto objetivo:

“...en el concepto objetivo es donde formalmente, se nos presenta 'lo que' la cosa realmente es, por esto es por lo que esta presentación es, en cierto modo, una 'segunda' presentación de la cosa misma, es decir, su 'representación'."(SE. 59).

Aparición de la noción de Inteligencia Sentiente:

"Formar conceptos es una función ulterior que reposa sobre esta otra función primaria y que deriva de ella... Por tanto, antes de una verdad ontológica 
(que bien pudiera llamarse una verdad conceptiva) hay una que llamaré 'verdad real' que es fundamento de ella.... La esencia de la cosa se halla envuelta en esta verdad real, y por consiguiente, es un momento intrínseco de la cosa.." (SE. 65)

La esencia como unidad estructural:

"Porque aquí no nos preguntamos por la cosa en cuanto posee notas múltiples, sino en cuanto posee una interna unidad estructural, la esencia en efecto, no es una adición de notas compatibles, sino una unidad positiva de la cual aquellas notas no son sino momentos."(SE. 66)

Aparición del concepto de principio, o mejor lá esencia como principio:

"...como posibilidad interna de la cosa, la esencia no es un concepto incontradictorio, sino un principio real de la cosa real en cuanto tal."(SE 67)

Alusión a la distinción de objetividad y objetualidad, desarrollada precisamente en IRA:

“...Es que se confunde la 'objetividad de lo concebido en cuanto concebido, con lo que yo llamaría la 'objetualidad', esto es, el que algo sea objeto."(SE 70)

Llegado a este punto Zubiri va a enfrentarse con Aristóteles. La esencia como unidad metafísica 'definida' es una unidad específica. De ella sólo se 'benefician' las cosas que respondan al concepto de sustancia. Zubiri va a establecer para su diálogo con Aristóteles tres puntos, que a su vez constituyen su propio esquema en el trato del tema en el Libro:

1. "Acotar el ámbito de las cosas, que yo llamaría 'esenciables'."

2. "Indicar, dentro de este ámbito, cuáles son las cosas que tienen esencia, las cosas 'esenciadas'.

3. "Determinar en qué consiste formalmente la 'esencia de estas cosas'(SE $83)$.

La noción de sustantividad, como contrapuesta a la de sustancia para conceptualizar la realidad. La encrucijada, o convergencia que llama Zubiri, de las dos vías del logos y la fisis va a darnos la clave definitiva de que la inteligencia conceptiva no sólo no es la única viable para la inteligibilidad, sino que aun en su expresión 'más clásica' también nos aleja definitivamente de la realidad. Aparece, según Zubiri un dominio del momento de definición sobre el momento físico. Pero lo problemático está en que todo lo esenciable, o mejor lo esencial de toda cosa sea definible:

"Una cosa es averiguar qué es lo esencial de algo, otra que lo averiguado sea formalmente una definición. En lugar de mensurar la definición con la esen- 
cia y ver que aquélla recae tan sólo sobre un aspecto de la esencia, Aristóteles mensura la esencia con la definición." (SE 90)

El tema de la especie y de la definición nos aboca, a su vez al tema del individuo y a la esencia como función estructurante de la realidad sustantiva. En definitiva, al punto de partida de Zubiri desde una inteligencia no concipiente, sino 'sentiente':

"En lugar de afrontar la cuestión de la esencia por sí misma, y tratar de ver dentro de un individuo determinado en qué consiste su momento físico esencial respecto de la totalidad de notas que posee hic et nunc, lo que Aristóteles busca es algo distinto, a saber: cómo se articula este individuo dentro de la especie, la estructura de esta articulación sería la esencia."(SE 91)

\subsection{La verdad real y la actualización}

Ante la realidad misma hay que "inquirir en ella cuál es ese momento estructural suyo que llamamos esencia"(SE 97)

En cinco puntos resume Zubiri las conclusiones de su análisis de las concepciones sobre la esencia. Así podemos relacionar:

Contra Husserl:

1. La esencia es momento de una cosa real (también a propósito de Hegel)

2. Este momento es unidad primaria de sus notas

3. Esta unidad es intrínseca a la cosa misma.

Contra Aristóteles:

4. Esta unidad es un principio en que se fundan las demás notas (necesarias o no) de la cosa.

Contra Racionalistas y Hegel:

5. La esencia así entendida es, dentro de la cosa, su verdad, la verdad de la realidad. (ver SE 98)

El ámbito de lo esenciable es el ámbito de la realidad (SE 103). Es el tema de la realidad como fundamento de toda especulación sobre la esencia.

Definición operativa o descriptiva de la realidad:

"Es realidad todo y sólo aquello que actúa sobre las demás cosas o sobre sí mismo en virtud, formalmente, de las notas que posee". (SE. 104)

La actuación es la ratio cognoscendi. 
Distinción de cosa real y cosa-sentido en SE.105, que aquí aparece relacionada con Aristóteles, Husserl y Heidegger.

En realidad todo el sentido husserliano aquí viene a parar.

Como podrá observarse, ya está el 'de suyo', pero digamos que no explicitado, ya que en esa especie de depuración conceptual, primero nos va a determinar la noción de naturaleza:

"Frente al concepto moderno de naturaleza como ley, hay que reivindicar aquí el concepto de naturaleza como cosa. Pero frente al concepto griego de cosa natural, como cosa originada por un principio intrínseco, hay que propugnar el concepto de cosa que actúa formalmente por propiedades que posee, sea cualquiera su origen."(SE. 107)

De la naturaleza como ámbito de lo esenciable, vamos al paso siguiente: la realidad esenciada. Pero esta realidad esenciada no aparece tan a primera vista. Al hilo del análisis descriptivo del 'haber que tener' 'para ser tal'. Aparece un 'de' y un 'para' como determinativos de la necesidad esencial:

"...cuando un sistema de notas es necesario no para actuar en determinada forma, ....sino sencillamente para ser real..., sólo entonces tendremos necesidad esencial en sentido estricto. En tal caso el 'para' se identifica con el 'de' en el 'qué', desaparece la distinción real entre el 'de' y el 'para'. El 'qué' es la realidad misma del 'de', de suerte que ya ni puede hablarse en rigor de una 'de'. (SE 110).

Estamos ante la realidad simpliciter, a diferencia del secundum quid del 'para'. Así la realidad simpliciter de cualquier cosa natural (en sentido del concepto zubiriano) constituye lo que esta cosa es en verdad, es su verdadera realidad.

Aparece aquí la verdad real como apoyatura o fundamento de la inteligibilidad de la esencia.

“Con esto hemos circunscrito el área de lo 'esenciado': tienen esencia todas y solas las cosas reales en aquello y por aquello por lo que son realidad. Esto es, lo esenciado es la realidad simpliciter, la realidad verdadera. Tenemos la cosa en las manos, pero casi no hemos hecho sino alcanzarla y darle nombre propio, sin saber bien aún de qué se trata. Por tanto, es menester que digamos ahora con mayor precisión qué es esta realidad simpliciter. Entraremos en la cuestión del análisis de lo verdadero en la realidad." (SE 111)

Este último párrafo habla por sí solo de la metodología de Zubiri. La verdad real es la vía de la realidad simpliciter de algo, i.d. el contenido de la esencia. Visto desde la Trilogía, ¿lo hasta ahora expuesto podría ser como el esbozo, cuyo sistema de referencia sería ese determinado actuar necesario de las cosas?. Sólo al final de estudio se podría contestar adecuadamente a esta cuestión. 
El capítulo VIII de 'Sobre la Esencia', cuyo título es 'la realidad -esenciada-', tiene como tres epígrafes que transcribo, pues entiendo que nos dan la clave última de Zubiri: la unidad. Decía al principio de este estudio que el saber de esta unidad (la que ella fuere), iba a constituir una filosofía primera; a este capítulo en concreto me refería.

\section{1. 'realidad y verdad' (SE 112-134)}

2. 'unidad estructural de la realidad simpliciter' (SE 135-142)

3. 'carácter formal de la unidad de lo real' (SE 134-174)

Análisis de lo verdadero de lo real:

"La verdad de que aquí se trata no es la verdad lógica, la conformidad del pensamiento con las cosas. Aquí verdad no es conformidad, sino algo más hondo: el fundamento de dicha conformidad [...]

Este otro sentido, el fundamento de la verdad significa aquello que hace que haya verdad en la inteligencia. Sin inteligencia, lo que 'hace' este fundamento no sería verdad, pero sin ese fundamento no habría en la inteligencia lo que llamamos verdad. A este fundamento en tanto que tal, es decir, como fundamento de la verdad de la intelección, le llamamos 'lo verdadero'. Aquí 'verdadero' significa, pues, que 'da verdad' si se me permite la expresión, lo que 'verdadea' en la intelección. En este sentido es en el que nos preguntamos por el fundamento de la verdad." (SE 112)

A propósito, he desgajado del párrafo transcrito el contenido de los puntos suspensivos [...], ya que dicho contenido constituye el planteamiento de la verdad para una filosofía de la Inteligencia, así como éste lo es para una filosofía de la Realidad. Consignémoslo ahora para que 'reluzca' este paralelismo verdaderamente aspectual:

“...Pero ¿de qué fundamento se trata?. Evidentemente sin inteligencia no existiría verdad. En este respecto el fundamento en cuestión sería la propia inteligencia y la búsqueda de este fundamento sería una teoría de la inteligencia. Pero aquí no nos proponemos una teoría de la verdad en este sentido, sino en otro..."(SE 112)

El primer concepto que aparece y no podía ser otro, es el de actualización, y contraponiéndolo con firmeza al 'equivalente' de sus interlocutores:

"En la verdad hay un momento de intelección: sin él lo que llamamos verdad no sería verdad [...]. Pues bien, aunque no hay verdad sino en la intelección, no es la inteligencia en y por sí misma lo que 'da' verdad a la intelección, no es lo que verdadea en ella... El acto propio y formal de la intelección respecto de lo inteligido es ser mera 'actualización' de la cosa en la inteligencia, y por tanto, lo inteligido en cuanto inteligido es tan sólo 'actualizado' [...]. 
Tomo, pues, la actualización como un simple hecho bien constatable, lo único que la cosa adquiere por la intelección es su mera actualidad en la inteligencia. Inteligir es un mero actualizar la cosa. Toda otra concepción es inaceptable ante todo por falta de radicalidad. Posición ideación, correlación intencional no podrían ser ni tan siquiera lo que pretenden ser ( $y$ a veces efectivamente lo son) si no fueran simples modalizaciones entre otras varias, de esto que es actualizar."(SE 113)

Tratamiento a parte dentro de esta falta de radicalidad, le merece la desvelación de Heidegger:

"La desvelación no es formalmente el acto de intelección, sino que es, a su vez, un carácter especial de la actualización. Si la cosa está desvelada es porque está àctualizada."(SE 114)

A la luz de esta actualización, ¿qué es exactamente, o mejor, formalmente lo que constituye verdad?; pues el mero hecho afirmativo de que la intelección es actualización de la cosa, no supone verdad. Es aquí donde aparece bien determinado el concepto de realidad:

"Porque, ¿de qué cosa se trata? La pregunta se refiere, naturalmente, no a cuáles sean las cosas que de hecho inteligimos, sino al carácter formal de lo inteligido en cuanto tal. Pues bien, este carácter formal es "realidad'." (SE 115)

En esta intersección de Inteligencia y Realidad en la verdad, aparece nítidamente el momento del prius:

"En su actualización como realidad, pues, la cosa real funda la verdad, pero se actualiza a sí misma como algo que si es fundamento, lo es precisamente porque ya era realidad propia independientemente de la intelección, de suerte que en la actualidad intelectiva de la realidad, el momento de realidad se nos presenta como un prius respecto del momento de su actualidad intelectiva." (SE 116).

Al determinar más esta verdad real va a aparecer 'incoado' bajo el término de 'remisión', el concepto zubiriano de respectividad; y la insinuación del tipo de unidad que subyace a la dualidad de condiciones.

En el análisis de la verdad real es fundamental la forzosidad de la realidad que nos hace quedar retenidos, este quedar forzoso, es el estar. Ello es el fundamento en IRE de la modalización de ratificación (mejor de aprehensión primordial). Así la verdad real es el hilo conductor para el análisis de la realidad.

En la actualización de aprehensión primordial se da actualizada la nota que remite en su misma actualización a la realidad de la cosa de la que es nota real. Pienso que es así como hay que analizar el párrafo anterior. Desde la actualidad va a salir una forma nueva de considerar las categorías, - de dentro a fuera-, 
la dimensionalidad de la realidad y su unidad estructural. Veámoslo en apretada síntesis:

"Se parte de la cosa y vemos en las notas no algo que un sujeto tiene, sino aquello en que la cosa es actual (SE 125)... en esta... visión de que hablamos, no se trata de un 'brote', sino de una 'actualización' o 'proyección' de la cosa real en la totalidad de sus notas. Y además es una proyección tal que puede tener lugar de diversos modos, en distintos respectos formales.... cada uno de ellos es justamente lo que llamo 'dimensión' porque en cada uno de ellos se mide o mensura la cosa real entera.... En rigor se trata de 'respectos formales' de la actualidad de una cosa en sus notas, y en cuanto respectos son distintos. Si los llamo dimensiones es porque en cada uno de ellos se mide o mensura la realidad de una cosa, y porque como respectos son los primarios (SE 126)...

Siendo la realidad pluridimensional, la proyección de la realidad en cada dimensión dará lugar a un modo preciso de ratificación... a un modo preciso de verdad real... "(SE 127)

Estas dimensiones nos descubren la fundamentalidad. Veámoslas en esquema. (En IRE 240, y rectificada por el mismo Zubiri, se da una distinta conceptualización, que a mi manera de entender, y a salvo de un análisis más minucioso, se debe a que en "Sobre la Esencia" está bajo la preocupación de 'despegarse' de la desvelación heideggeriana):

Primera dimensión

- El respecto de las notas: patentización

- El modo de actualización de la cosa en las notas: riqueza

- El carácter descubridor de las notas: manifestación (ver SE 128)

Segunda dimensión

- El respecto de las notas: confianza (mejor, seguridad)

- El modo de actualización de la cosa en las notas: solidez

- El carácter descubridor de las notas: firmeza (ver SE 129)

Tercera dimensión

- El respecto de las notas: estar siendo

- El modo de actualización de la cosa en las notas: efectividad

- El carácter descubridor de las notas: constatación (ver SE 130-131)

"Las tres son congéneres como momentos estructurales de la primaria actualización intelectiva de una cosa real. Sin embargo son formalmente distintas, tanto que su despliegue en intelección ulterior matiza fundamentalmente la actitud del hombre ante el problema de la realidad." (SE 131). 
Tenemos desde el punto de vista de Zubiri una auténtica experiencia, en este análisis de la verdad real, de la "intrínseca contextura dimensional en toda su plenitud de lo que la cosa es: riqueza, solidez, estar siendo". (SE 133)

El fondo de la realidad es dimensional, de ahí el paso siguiente, LA UNI$D A D$ : "la índole de la realidad esenciada se halla en la unidad primaria de estas tres dimensiones estructurales de la realidad." (SE 134)

La unidad estructural de lo real es "constitución" (ver SE 142); ahora veamos la determinación de este concepto:

"Hay que comenzar... por discernir cuál es el tipo de notas de la realidad simpliciter." (SE 135)

El criterio será, de las notas que una cosa posea hic et nunc, cuáles son momentos de su rico y sólido estar siendo. Todo este planteamiento hay que verlo desde una inteligencia sentiente, frontalmente opuesta a una inteligencia concipiente. Físico, como contrapuesto a conceptivo. Individual 'por sí mismo', y no como referencia a un supuesto principio de individuación:

"La determinación interna no desempeña primariamente una función diferencial, sino una función constitucional propia de la cosa." (SE 139)

El concepto estricto de constitución lo formula así (los subrayados son míos):

"Las unidades no difieren tan sólo por su contenido, sino también por su propio modo de ser unas. En toda realidad individual estricta hay una unidad de contenido de sus notas y una unidad meramente numeral, según la cual aquella realidad es irreductiblemente 'esta', 'una'. A esta modulación es a la que llamo determinación interna. Pues bien, la unidad numeral así modulada o determinada es lo que entiendo por constitución: es el modo propio que 'cada' cosa tiene de ser 'esta', de ser numeralmente una, si se quiere, la indole del 'ser-unidad'. Así pues, el 'modo' intrínseco y propio de ser física e irreductiblemente 'uno' es justamente lo que llamo filosóficamente 'constitución'."(SE. 140)

Con este concepto de constitución vamos ya al carácter formal de la unidad de lo real:

“...la unidad constitucional... es unidad primaria... cada nota es función de las demás... la unidad domina, es un prius respecto de la posesión de cada nota aisladamente considerada."(SE. 143)

He aquí un concepto clave (respectividad-actualidad): una determinada estructura que se conceptúa por su unidad (formalmente). A ello denomina Zubiri con la expresión funcional de la 'posición':

La noción de sistema como expresión de la unidad primaria nos aboca a una noción clave en la determinación de la cosa real como real, la sustantividad: 
"Lo que la constitución constituye es una sustantividad, y la realidad así constituida es una realidad sustantiva. Esta cosa en cuanto sustantiva es el sistema mismo." (SE 147)

La sustantividad es un carácter del sistema. La constitución constituye una sustantividad. Así la realidad esenciada — realidad simpliciter-, será una realidad sustantiva. ¿Cuál es su estructura? :

“La sustantividad... envuelve un carácter de suficiencia." (SE 151)

En fórmula apretada: sustantividad, unidad sistemática y posicional.

"Lo formalmente decisivo de la sustantividad no es la originación sino la interdependencia posicional en el sistema, la posición en él. Sólo es formalmente sustantividad la unidad sistemática y posicional de estas notas. Recíprocamente, las notas no son sino actualización física de la suficiencia constitucional de la sustantividad. Y los distintos respectos formales de la suficiencia son justamente las dimensiones. Riqueza, solidez, estar siendo son dimensiones de suficiencia constitucional." (SE 157)

La realidad humana es para Zubiri el ámbito donde aparece en toda su 'existencialidad' la verdad de esta visión de la realidad, o mejor su actualización.

Determinado el ámbito de la realidad esenciada como unidad estructural de la realidad simpliciter, - sustantividad individual-, en realidad nos encontramos ante la 'esencia' misma de lo real.

Si volvemos ahora, sólo por unos instantes, la vista a las aproximaciones de la primera parte del estudio, nos encontramos con lo siguiente:

Una inteligencia sentiente, que en su modalización de aprehensión primordial de realidad tenía verdad real, y esta verdad real, como tal aproximación a la ' $y$ ' de Inteligencia-Realidad, en despliegue intelectivo se resolvía en la $3^{\text {a }}$ aproximación: la respectividad.

Curiosamente, también ahora nos vamos a topar de inmediato con esta noción de respectividad en 'Sobre la Esencia'.

\subsection{Realidad y Respectividad}

El título de este apartado tendría que ser explicado para que ya desde este momento se entendiera el por qué la respectividad juega un papel decisivo en la comprensión de la esencia como principio. Baste con decir de momento que si la intelección sentiente es un despliegue 'en hacia' la realidad. La esencia constituye el principio del repliegue de la realidad 'en hacia' sobre la intelección. Al final de apartado aclararé esta idea. 
Aparición de la respectividad a propósito del carácter y la función propia de la esencia ${ }^{3}$ :

"Ciertamente toda realidad es, desde cierto punto de vista, 'respectiva'. La realidad es 'sintáctica'. Pero esto no quiere decir que esta respectividad o sintaxis sea el 'orden resultante' de las acciones o pasiones. Todo lo contrario. Las acciones o pasiones son consecutivas a la respectividad en que se hayan las cosas reales por su propia constitución entitativa. Precisamente porque la realidad es respectiva, cada una de las cosas reales tiene su constitución 'propia' en orden de respectividad. " (SE.181)

La función de la esencia en orden a la suficiencia:

"La esencia no es esencia por las notas según su consideración absoluta, sino según la función que estas notas desempeñan en la cosa real (SE 183). La función física y individual y constitucional de la esencia es una función en orden a la 'suficiencia'..."(SE 185)

¿Qué tipo de principio es la esencia dentro de la realidad sustantiva?:

“...la esencia ha de fundar, dentro de la realidad sustantiva, tanto los determinantes de su modo de unidad como la unidad misma. Sólo habiéndolo entendido así habremos aprehendido la esencia en sí misma y su función; y estaremos en condiciones de conceptuar el tipo de principio que es la esencia dentro de la realidad sustantiva." (SE 187)

La esencia como sistema de notas constitutivas $=$ realidad simpliciter:

"Recordemos que 'constitución' tiene un sentido filosófico estricto: es el sistema de notas que determinan el modo intrínseco y propio de ser algo física e irreductiblemente 'uno', esto es, sustantivo... llegar a una nota constitutiva es un problema siempre abierto..." (SE 190)

“Como por su condición metafísica, la esencia es absoluta o... factual. Por su carácter entitativo, la esencia es ultimidad individual. Por su contenido constitutivo, la esencia es inalterable." (SE 195)

Condición, hay que entenderla como el carácter intrínseco que tiene la cosa en su manera de ser real respecto de un 'fundamento'.

Hablando en concreto de condiciones metafísicas, aparece el tema mundo y Dios. Consigno solamente aquellos aspectos que pueden ser útiles para el presente estudio:

"Necesidad y contingencia... no son momentos estructurales formales de la realidad, sino caracteres intrínsecos de ésta en su manera de ser real respecto a su fundamento intramundano, es decir condiciones metafísicas... Con la libertad tocamos a una nueva condición metafísica. Lo libre es ciertamente contingente. Positivamente lo libre está por encima de lo necesario y de lo 
contingente: es el modo de ser del dominio del acto, la 'dominancia'." (SE 203)

Lo posible como potencial: hecho. Y lo posible como posibilitante: suceso (como realización). En 'Inteligencia y Razón' aparece detallada esta conceptuación y a ella hay que remitirse.

En el análisis de la unidad de la esencia sale al paso la unidad quidditativa de la esencia, o si se quiere mejor la esencia quidditativa. En realidad desde la concepción de Zubiri del Logos, esta cuestión queda zanjada de raíz. Baste de momento consignar esta cita;

"El quid, la esencia estricta, significa en primer lugar el conjunto de notas constitutivas de una cosa... En segundo lugar, dentro de esas notas, aquellas o aquellos momentos suyos que son articulables en forma, por ejemplo, de género y diferencia. Sólo este último quid, sólo esta esencia, es quiddidad, a saber, especie..." (SE 228)

En el análisis de la esencia quidditativa, las nociones que maneja Zubiri, son la multiplicación (proceso físico de 'producir' multitud) y el phylum (la razón radical de la especiabilidad es la multiplicabilidad filética, y la razón formal de la especie es capacidad de pertenencia actual o virtual a un 'phylum'. (ver SE 236)

Dando un paso más, llegamos al contenido mismo de la esencia: su mismidad. El hilo conductor es: mismidad, inalterabilidad, identidad. La distinción es precisa y aclaradora:

"La inalterabilidad... está precisa y formalmente en la línea de la mismidad. Toda nota, sea o no esencial, es susceptible de alteración física. Lo que sucede es que hay notas que al alterarse no alteran la mismidad de lo real... Entonces esto real deja, ciertamente, de ser 'lo' mismo, pero continúa siendo 'el' mismo. En este sentido y sólo en éste, es en el que decimos que las notas de la esencia constitutiva son inalterables...Ir contra la esencia es una contrarealidad, es la destrucción física de la realidad sustantiva."(SE. 249)

"La identidad... es a lo sumo el concepto objetivo de la mismidad." (SE 250)

La esencia constitutiva por razón de su contenido posee ultimidad de mismidad.

La inalterabilidad constitutiva del contenido de las notas esenciales es así paradójicamente una génesis de esencias.

El concepto estricto de generación se determina como repetir, engendrar, originar:

“Empleando el concepto griego de 'génesis', diremos que toda esencia constitutiva es término genético de otra, y que esta génesis incluye las tres posibilidades de repetir, engendrar y originar." (SE 254) 
El marco cósmico-mundanal ${ }^{4}$ de la esencia en su contenido nos lleva a las nociones de configuración y potencialidad:

Ultimo punto antes de entrar de lleno en la unidad de la esencia: la esencia como momento fundante de la sustantividad:

“La sustantividad no está constituida por 'estratificación' sino por 'determinación' unitaria. (SE 264)... Esta determinación, que no es 'originación', es a lo que yo llamaría determinación meramente 'funcional'...y lo que esta función determina es lo que he llamado 'posición' (SE 265)... En la determinación funcional entran en juego para cada nota, la totalidad de las notas constitutivas de la sustantividad." (SE 266)

Esta determinación funcional es construcción: esencia-sustantividad-sistema-:

Llegados a este punto sólo nos resta determinar este momento de la esencia (momento físico y por tanto individual), como término de qué tipo concreto de saber:

Esto supuesto vamos a entrarle a fondo a la unidad de esa estructura formal y última de la 'realidad'.

La unidad esencial es una unidad que se actualiza en el haz de notas esenciales por sí mismas. Ese 'por sí mismas' conlleva una capacidad de... unidad. Es una auténtica solidaridad física por contraposición a una incontradicción. Y esta unidad es como una especie de apriori (alusión a Kant en este planteamiento) fundado en la respectividad:

“...las notas son la 'posibilidad interna' de la esencia... in re, físicamente, las notas no sólo no son independientes... son justamente 'solidarias'... la una no puede darse, físicamente, sin la otra." (SE 281)

¿Cómo se entiende la actualidad de esta unidad?(ver SE 283)...

1. La esencia es un sistema de notas constitutivas... en cuanto sistema es algo 'uno', es una unidad esencial.

2. Esta unidad esencial es un carácter en orden a formar sistema por si mismas... ultimidad... un sistema dotado de suficiencia...

3. Este 'por sí mismas' no significa 'en sí mismas'...

4. Este momento físico del 'por sí mismas' tiene dos aspectos... es intrínseco ('desde sí mismo') y es primario ('de antemano'). Por consiguiente, ser intrínseca y primaria: he aquí los dos aspectos de la unidad esencial.(ver SE 286)

Este es el punto central de la metafísica de Zubiri: la unidad de la esencia. Aparecen aquí las nociones claves de la concepción de Zubiri: respectividad; estado constructo para 'ejemplificar' la respectividad y al mismo tiempo como 
órgano de conceptuación de la esencia, en contraposición a los tipos de unidad clásica: conjunción, adición, ordenación, inherencia, sustancia. La unidad que manifiesta el constructo es unidad de coherencia. (Dejo de tratar, por razones obvias, el tema de la esencia como rasa, ya que entiendo que Zubiri lo trae para aclarar su conceptuación del constructo):

“...La versión no es ya propiamente una 'relación', ...esta versión... no sólo no presupone la nota sino que es uno de los momentos que la constituye en su realidad física. Este carácter constitutivo de la versión es lo que he solido llamar 'respectividad' (SE 287)

Estado constructo por contraposición al estado absoluto. Lo que es absolutamente intrínseco a unas notas es serlo de 'alguien', entiéndase en general a su propia unidad sustantiva. Dicho de otra manera, lo único que tiene carácter absoluto 'es el sistema mismo'. (ver SE 292)

“...el término absoluto de las notas esenciales no es un sujeto, sino la unidad misma de todas las notas. De donde se sigue que sólo son 'notas-de' aquellas que por sí mismas y de un modo directo forman sistema." (SE 297)

Desde esta unidad coherencial, Zubiri vuelve sobre el concepto de generación para determinarlo así definitivamente. Veámoslo esquemáticamente: el esquema constitutivo en la generación, replicación de la constitución, re-constitución. Generación es un fenómeno de la sustantividad: un momento de la esencia constitutiva. Esencia quidditativa, un momento de la esencia constitutiva. Phylum es así un esquema constitutivo replicante.

Con esto queda claro la unidad coherencial en su momento de 'desde sí misma', unidad intrínseca. El segundo aspecto, el de 'ante mano', es el que resta por dilucidar.

El concepto clave respecto de 'el antemano' es el concepto de dominancia. En la exposición misma del esquema, se podrá observar que esta dominancia es exigencia de la realidad actualizada en la unidad coherencial. De ahí que las notas como tales sean analizadoras de la unidad como tal.(ver SE 322)

En la esencia el momento absoluto es la unidad misma del sistema. 'el' Ser y 'lo' Uno (ver SE 326) carecen de sustantividad. Lo 'uno' es sólo momento de la sustantividad. No es nota sino unidad de notas.(ver SE 327)

La unidad está en cada nota como dominándola en su realidad física (ver SE 328). Cada nota 'exige' el todo de las demás: momento exigencial, —perseidad exigencial一.

Todo ello se esclarece distinguiendo claramente el orden operativo y el orden entitativo. El orden operativo pertenece a la actividad del gigneszai. El orden entitativo es la actualidad de la entelequia. Citemos la página de "Sobre la Esencia", que me parece de las más lúcidas: 
"De suyo, pedir, exigir, reclamar, etc., son términos que sólo tienen sentido claro en el orden operativo, pero hay que trasladarlos al orden entitativo, al orden sustantivo. Otros términos metafísicos están en la misma situación. Por ejemplo, cuando Aristóteles quiso conceptuar metafísicamente la materia prima, tomó el concepto de potencia (dynamis) del orden operativo, y por un esfuerzo de abstracción lo traspuso al orden entitativo, la materia prima (prote yle) sería la potencia de su forma sustancial, la cual sería el acto de aquella. Pero antes había tenido que realizar la misma transposición mental para conceptuar entitativamente lo real como ente en 'acto'. Difícil esfuerzo fue. El concepto de acto es claro, en el orden operativo, tratándose... de las acciones humanas. Tomemos el caso de que alguien ejecuta una obra (ergon). Consideremos en esta acción primero la operación misma y después lo operado, la obra. El que ejecuta una obra está en actividad (en energeia), y en este sentido operativo, actividad se opone a pasividad o afección, pazos. Pero Aristóteles necesita trasponer el concepto al orden entitativo. Para ello, si en la actividad en que se está al producir una obra, me fijo no en aquello en que se está, es decir, en la actividad, sino en el hecho mismo de estar en ella, es decir en el hecho de estar actuando, entonces energeia no se opone a pasividad, pazos, sino a potencia, dynamis, y viene a significar no actividad, sino actualidad. Con lo cual, en el orden entitativo, energeia vino a significar la actualidad de lo real. Por otra parte fijémonos en la obra misma. En la acción del hombre se va produciendo la obra, hasta que la acción acaba, termina. Esto, en el orden operativo. Pero si considero la obra no en cuanto operada o ejecutada por mi acción, sino que me fijo en la obra en sí misma, entonces 'acabamiento' no significa que la acción termina, sino que la obra es algo 'acabado' y terminado en sí mismo (entelejés, perfectum). Este momento de acabamiento es un momento entitativo de la obra: lo real es entelejeia, actualidad en el sentido de plenitud por oposición al devenir (gigneszai). Por donde entelejeia viene a converger con energeia para designar y conceptuar lo real como actualidad." (SE 330)

El esfuerzo de la mente por conceptualizar el orden entitativo desde el lenguaje operativo. ¡Página magnifica! Exigencia que pertenece al orden operativo, en su significación 'directa', en el orden entitativo es el carácter de la unidad coherencial: el modo de estar la unidad no es parousia, sino dominancia exigencial. (Aquí culminaría el orden de la actuidad, a lo que yo entiendo).

La 'persecución analítica' del hacer de la unidad en el orden entitativo: prioridad-realidad-actualidad (actuidad). Pero bien entendido que la unidad esencial conlleva el momento exigencial.

"Cada nota en 'estado absoluto' nada tiene que ver con el contenido absoluto de las demás. Pero este estado no tiene por sí mismo realidad física completa, porque ninguna nota está dentro de una esencia en este estado, la esencia, en efecto, no es un mero conglomerado de notas." (SE 333) 
De estados absolutos sólo sabrá la razón con sus esbozos construidos, pero esto ya es otra cuestión: es el orden de las verdades racionales sobre la realidad de las cosas en cuanto tales realidades. Pero el saber de los caracteres de la unidad coherencial de la sustantividad en su momento esencial, pertenece a una filosofía primera, que entiendo que es lo que Zubiri persigue denodadamente en este obra de 'Sobre la Esencia'.

La función propia de la unidad coherencial es 'esenciación', y la índole formal de las notas, en cuanto realidades esenciales, es ser 'esenciadas'. (ver SE 334).

Y ya rematando este largo y difícil apartado, como no podía ser menos, aparece la respectividad como última claridad sobre la estructura de esta unidad de la esencia:

"La unidad. no es algo oculto por debajo de las notas, ni algo fuera de ellas, sino que es algo real tan sólo en ellas mismas, es su sistema mismo, su respectividad... La primariedad de la unidad no es la prioridad fontanal de unas notas sobre otras, sino la prioridad de la respectividad interna sobre cada una de las notas respectivas." (SE 335)

Habla aquí Zubiri de una otra respectividad externa refiriéndose al mundo, la respectividad estructural de las cosas. Una vez más vuelvo a constatar que se trata propiamente de cosmos, y que el saber de ella sí es propio de la razón. Pero la actualidad de la unidad 'en' cada nota y cada nota actualizada como siendo 'nota-de' es algo dado en aprehensión primordial de realidad. $Y$ así cobra toda su fuerza ante la vis unificante de la sustancia de Leibniz (ver SE 340), o el 'devenido' de Hegel (ver SE 341).

\subsection{Esencia y Re-actualización}

Propiamente una vez 'aprehendida' la esencia como momento de la sustantividad, momento fundante de la realidad sustantiva (las dos fórmulas son idénticas), el decir de este momento es un logos. Un logos que es modulación de intelección impresiva. Desde una inteligencia sentiente la proposición sonaría así: qué es el qué de la realidad en realidad. Ese 'en realidad' es talidad. El desarrollo de esta idea, es el contenido de este apartado. Procederé como en los anteriores, al hilo de "Sobre la Esencia"...

El lenguaje no sólo como expresión, sino en su sentido más estricto de significar expresando:

“...entre toda expresión, sea o no lingüística, y la mente misma hay una intrínseca unidad honda y radical: la forma mentis. Esta unidad... esta mente así 'conformada', es la que precisa y formalmente llamamos 'mentalidad': mentalidad es forma mentis, Por esto es por lo que, el legein, no es sólo un 
decir 'algo', sino que es decirlo de 'alguna manera', esto es, con ciertos módulos propios de una determinada mentalidad." (SE 345)

Toda estructura de lenguaje deja traslucir una estructura conceptual; esto es lo decisivo, ya que todo logos deja abierto siempre el problema de su adecuación primaria para concebir lo real.

Independientemente del segundo tomo de la trilogía, donde el desarrollo del logos, digamos queda definitivamente aclarado ${ }^{5}$, aquí en 'Sobre la Esencia', está suficientemente centrado. Veámoslo en esquema:

El logos predicativo de la filosofía clásica: la definición conlleva:

- Identificación del logos esencial con la definición

- Identificación del logos esencial con el logos predicativo

- Identificación del logos con una realidad subjetual. (ver SE 347)

La forma primaria de la aprehensión afirmativa de lo real es la forma nominal:

"Antes de la división del logos en simple aprehensión y afirmación predicativa hay un logos previo, que es, indiferentemente, lo que he solido llamar una 'aprehensión simple que es, a la vez y simplemente, denominación afirmativa de lo real. Es un logos ante-predicativo, el 'logos nominal'." (SE 353)

Este logos nominal reviste formas diversas, dependiendo de las formas nominales mismas. Yendo directamente a la forma de la esencia ya conseguida (constructo), el logos nominal será un logos nominal constructo. Es la conceptuación de la esencia en función de la 'constructividad' intrínseca. La esencia (realidad actualizada de su propia y actual exigencia intrínseca), tiene unas notas en estado constructo, notas-de, y estas notas tienen una unidad (unidad coherencial primaria), que es el momento absoluto en ellas.

Así queda determinada y 'ex-presada' la esencia, no como sujeto, ni sustancia, ni conjunto de esencias, ni razón, sino como momento cuya estructura es unidad primaria. Y esta "realidad constructa de la esencia puede considerarse desde dos puntos de vista que responden a dos aspectos de la realidad esencial: talidad y trascendentalidad" (SE 356).

Creo que el enfoque es claro, y sólo queda que el desarrollo — sin interrupciones-, así nos lo muestre.

La esencia de lo real 'determina' todos los caracteres que posee una cosa 'tal' como es. El 'cual' de ese 'tal' es asunto del saber positivo. A la metafísica corresponde la conceptuación de la 'talidad' misma. (ver SE 357)

La talidad hay que conceptuarla en función de la constructividad del sistema (ver SE 358). El contenido pertenece a la esencia sólo en virtud del 'de' (ver SE 
359). Ser nota-de, igual a ser contenido-de: es lo que hace de la esencia 'tal' esencia.

El modo de tener las notas es lo que constituye la talidad.

Constructividad de notas físicas, igual a notas-de. De ahí que la función talificante es formal y exclusiva de las notas-de. Autosuficiencia talificante. 360).

¿Talificante de qué?, del término absoluto, i.d. de la unidad misma (ver SE

En virtud de la primariedad de la unidad esencial, las notas entran en la esencia talificando la unidad. Actualizar las notas es 'hacerlas' talificantes: la unidad esencial es auto-talidad.

La comprobación, en el orden operativo: se da la normalidad en los seres vivos por la línea del equilibrio biológico estable. El desgajamiento da estabilidad por liberación: subtensión dinámica.

Como unidad de notas físicas, la esencia es una totalidad limitada en sụs notas (contra la Escolástica y Leibniz, en la cuestión de la infinitud de los predicados). La co-limitación de la talidad es una forma determinada de coherencia: clausura cíclica (entendiéndola como constructo, no como serie). (ver SE 369).

Orden de la talidad: es esencia constitutiva, aquello que constituye a lo real en ser 'tal'. Si está construida según esquema, tenemos la esencia quiddificable. De ahí, tenemos como resumen: unidad clausurada, cíclica y esquemática; unidad consigo misma, unidad comunicada, unidad comunicable.

'Esto' y no lo 'otro', he ahí el ser 'tal'. (ver SE 371)

La consideración del orden transcendental de la esencia, digamos que remata la 'visión' zubiriana de la 'intelección' de la esencia. Siguiendo su diálogo con los grandes de la historia del pensamiento, este es el punto álgido, donde de alguna manera recoge lo dicho por cada uno y desde la perspectiva de lo transcendental.

Transcendental es un término equívoco por lo que a lo sistemas filosóficos se refiere. Así en Descartes, su idea de la filosofía: meditación sobre la realidad, apoyada en la realidad del yo. La unidad de esta 'apoyatura' es la verdad. El orden transcendental se constituye en el yo como realidad pura. Hay dos yoes. El yo empírico, cada yo es distinto de los otros. $Y$ un yo puro, distinto de las cosas, que son ob-jecta. , lo trascendental es ir a los objecta.

Así en Kant: sistema de formas conceptuales, el yo cognoscente.

En Husserl, intencionalidad constituyente, el yo consciente. Los objecta son 'puestos' por el 'hacer' del yo. El ser es objetualidad. Aquello en que convienen 
y tienen que convenir las cosas es en ser objetos: y esto es la trascendentalidad. (ver SE 374-375).

El conjunto de objetos determinados por esta unidad de objetualidad es lo que constituye para el idealismo la experiencia. El concepto de lo transcendental para el idealismo se constituye en la contraposición entre experiencia y transcendencia.

En el análisis que hace la filosofía medieval de su concepto del orden transcendental (el orden del ente en cuanto ente), como tal, es el mismo concepto de la filosofía moderna. De ahí que las puntualizaciones de Zubiri vayan para ambos y en conjunto. Veámoslo en esquema:

'Yo', no es la realidad del sujeto, sino al revés: es la realidad del sujeto la que tiene como propiedad el ser un 'yo' (no es momento entitativo). Lo propio del 'yo' es, no ir hacia el objeto, sino actualizarlo en la inteligencia.(ver SE 380)

- Contra Descartes: el momento de realidad es un prius. El yo es independiente por ser real y no viceversa. A la realidad le es indiferente tener verdad.

- Respecto de Kant, la postura es radical, y aparece aquí la intelección como actualidad, punto de encrucijada de la filosofía de la Inteligencia:

“...aun en el caso de estar inteligiendo un objeto, una res objecta, lo que formalmente intelijo no es la res en tanto que objecta, sino en tanto que res. Una vez más, aun en el caso mismo de los objetos, el momento de realidad se me presenta en la intelección mismo como un prius no sólo de su verdad, sino de su objetualidad. Contra lo que el idealismo afirma como algo obvio, cosa no es objeto. Así como sustantividad no es subjetualidad, así tampoco realidad no es objetualidad. El orden de la realidad en cuanto realidad no es el orden de la objetualidad, sino el orden de la simple realidad en cuanto realidad." (SE 382)

Para la Escolástica el esquema del orden transcendental puede describirse de la siguiente manera:

Ser —ente- es se in anima: como esse reale y ens rationis. El ens como sustantivo participial, o sujeto de una acción designada por verbo: infinitivo sustantivado-apto para ser. Así la cosa en cuanto apta para tener este esse infinitivo, se denomina essentia. Es un quid en cuanto que connota aptitudinalmente el acto de existir.

Así los tres momentos del esse: esse essentiae, existentiae, y logicum, entran de alguna manera en el acto intelectivo. De aquí que viniera en afirmarse a la inteligencia facultad del ser. (ver SE 385-386) 
Para la Escolástica, el orden transcendental es el orden del ente real nominalmente considerado, el orden del ente apto para existir, ordo entis ut sic. Como este ente viene a ser la psije de Aristóteles, de aquí deducirá la Escolástica los transcendentales: ens, res, unum, aliquid, verum, bonum. $Y$ este es el orden trascendental para la Escolástica. (ver SE 388). Este orden viene a ser pues, aquello en lo que todo conviene independiente de su talidad.

El enfrentamiento con la Escolástica pone a Zubiri una vez más, ante su propia radicalidad: realidad y existencia no son lo mismo.

“El acto propio y formal de la inteligencia no es 'concebir' sino aprehender

la cosa misma, pero no en su formalidad 'estimúlica', sino en su formalidad

'real'. Concebir es una función ulterior fundada en este primario modo de enfrentarse con las cosas. porque las cosas no están presentes solamente en los conceptos, sino también en el sentir." (SE 392)

Como se puede observar de aquí parte una filosofía primera del acto de inteligir en su actualidad: qué es lo real en la realidad: su esencia, -metafísica- Y Y el carácler intelectivo de lo real (la mera actualidad de realidad sobre lo que trata enteramente la Trilogía).

La tesis de Zubiri, se hace aquí explícita: las cosas antes que en el concepto, están presentes en el sentir. Y lo problemático será siempre que lo real no aparece en el puro sentir $r^{\text {t }}$.

En lo real: realidad-inteligencia; estructura-unidad-sistema, de aquí partirá siempre Zubiri.

El estímulo también es extra-animam. Pero la cosa-estímulo es irreal. Lo afectante, su unidad pende de la formalización.(ver SE 394). No es la independencia, ella se da también en el estímulo, sino el momento de prius = de suyo. El de suyo, es una explicación (no definición). Lo explicado queda así en la línea no del concepto, sino del enfrentamiento con las cosas.

De suyo y existencia: lo que constituye formalmente la realidad es el modo de existir: existir 'de suyo'. Lo que es 'de suyo', metafísicamente es el 'aparecer', la 'apariencia'.

La ambivalencia de la figura aparente es 'espectro' (concepto metafísico) de realidad. Así sólo cuando esencia y existencia conforman 'de suyo', tenemos realidad.(ver SE 399)

El 'de suyo' como ex se, para diferenciarlo como conceplo, de las posturas escolásticas.

La anterioridad de la realidad respecto a la 'essentia y existentia': la razón formal es anterior respecto aquello de lo que es razón formal (SE. 400). 
El quid metafísico: partir de lo real qua real. Después vendrán las consideraciones existenciales, esenciales, aptitudinales, etc.

El carácter érgico de la realidad, presupone la realidad.

A este nivel sólo queda tratar el tema del ser y realidad. Como lo aborda desde el punto de vista del logos afirmativo (esse copulativo) de ahí las consideraciones lingüísticas. En realidad, desde este punto de vista el tema está exhaustivamente desarrollado en IL. Aparece aquí la tesis de Heidegger (ver SE 411), pero lo veremos en el capitulo siguiente.

Por lo que respecta a nuestro estudio, cierro este apartado con una cita que pienso pone un punto de claridad y definitivo, sobre la $4^{\mathrm{a}}$ aproximación de la primera parte: la reactualización. Confluyen aquí por distintas vías de actualización: ser, logos y razón.

"El juicio consiste formalmente tan sólo en la intención afirmativa, la complexión real es aquello sobre lo que el juicio recae (SE 406)... La intelección afirmativa... envuelve a una tres momentos: la realidad, el 'ser' copulativo o intención afirmativa, y la verdad. su posible unidad.... no está en su 'ser' larvado en la 'realidad', sino en la unidad de desdoblamiento en la inteligencia (SE 408)..... 'ser' es algo independiente de la intelección, las cosas, ellas, 'son'. Por tanto 'ser' es un momento de lo real, es una actualidad de lo real, que le compete por sí mismo, aunque no hubiera intelección." (SE. 410)

\section{Inteligencia Sentiente: Saber Primario y Principial}

Las cosas empiezan y terminan donde empieza y termina el 'de suyo'. Toda teoría de la inteligencia lleva aparejada una teoría de la sensibilidad. La apertura a las cosas como realidad, es lo que constituye formalmente la inteligencia: la realidad es algo formalmente sentido, no concebido. (ver SE 414)

"Impresión no es la designación de un objeto sentido, sino que es la designación del modo como algo es sentido... En la intelección sentiente (o sentir intelectivo), por ser sentiente, lo aprehendido lo es también primariamente en modo de impresión. Sólo que lo que impresiona no son solamente cualidades estimulantes, sino cualidades estimulantes 'reales'. Lo cual significa que en la intelección sentiente, la impresión tiene dos momentos: Uno, el momento de cualidad sentida, otro, el momento de su formalidad real. Ambos momentos pertenecen a la cosa que me es presente sentientemente, y el modo como me son presentes es, para ambos momentos, impresión." (SE 415)

Si he puesto aquí esta cita, no es por lo que tiene en este momento de novedad (el desarrollo de esta idea es la obra de la Trilogía), sino porque el análisis que sigue nos va a mostrar cómo "Sobre la Esencia" es obra de una inteligencia sentiente que busca su propio objeto, que por ser 'primario' lo constituye en el objeto de una filosofía primera, en el saber de un principio que por 
ser fundamento, actualiza en intelección sentiente la estructura unitaria de su propia esencia.

La impresión de realidad es constitutivamente transcendental. El primer inteligible es lo real sentido (en primariedad de adecuación):

"Lo transcendental está ya dado en la impresión de realidad. Aquello que primera $\mathrm{y}$ formalmente es inteligido sentientemente, $\mathrm{y}$ aquello en que se resuelven todos los conceptos de la inteligencia, no es ente, sino realidad." (SE. 416)

Y el primer cognitum, en primariedad de origen, es la realidad en impresión (impresión de realidad). El 'prius' es el modo mismo de presentarse.

La reflexión que queda por hacer es una reflexión sobre el orden qua orden. Y aquí creo que sí podemos decir que el saber del orden talitativo, como tal orden, es lo propio de los saberes positivos. Y del orden transcendental como tal orden, es propio de la metafísica.

La maduración del concepto de mundo que aparece en la Trilogía también pone un punto de claridad en la determinación del concepto de 'mundo' que aparece en las pp.427-433 de "Sobre la Esencia". Dicho esto, vamos a movemos en una línea esquemática y directa, dejando aspectos más críticos para futuras reflexiones.

“Precisamente porque 'realidad' es un carácter meramente transcendental, no sólo está implicado en todo momento talitativo, sino que, recíprocamente, la talidad 'determina' (digámoslo asî) in re las propiedades de lo real en cuanto real, esto es, sus propiedades transcendentales. Y como estas propiedades no se identifican, sin más, con la talidad, resulta que la talidad misma se puede considerar según dos aspectos, según aquello que ella es en sí misma, y según aquello que trascendentalmente determina. $Y$ esto último es lo que temáticamente llamo 'función transcendental'. Esta función no se halla forzosamente limitada a la realidad de la cosa que es 'tal', hay en efecto, talidades, como la inteligencia y la voluntad, por ejemplo, que desempeñan una función transcendental no sólo respecto de la propia realidad, sino también respecto de toda realidad en cuanto realidad. Función transcendental es, pues, la función por la que una talidad constituye las propiedades transcendentales de la realidad... En virtud de esta función, la realidad en cuanto realidad... es 'formalmente' una verdadera estructura transcendental." (SE 425)

De aquí arranca, de esta función transcendental de la talidad, la respectividad como fundamento del 'lo que', i.e. de la talidad: las cosas son lo que son respecto unas de las otras, esta unidad es cosmos, y a lo que entiendo aqui subyace la noción qua noción de 'campo', como medio de intelección de lo que las cosas son en realidad. 
La función transcendental del cosmos (talidad) determina un mundo.

La actualidad de realidad en el mundo es ser. Estar en respectividad con las lemás cosas qua reales, esto es el ser. Realidad es formalidad absoluta. Ser, un :arácter respectivo. La sustantividad, anterior al ser: ser de lo sustantivo eactualización- (SE 435). Así la actualidad de realidad es previa a...., de aquí ie sigue que la respectividad de realidad a otras realidades será condición: poencial, actual, necesaria, posible, contingente, libre, etc.

Como actual en el mundo (ser), respectividad mundanal, su modalidad es el :iempo. (ver SE 436)

El ser es constitutivamente 'flexivo'. El tiempo es ser siempre otro:

- Fue-es-será pa- pre- fut

— Sólo lo extra-mundano es eterno

- Así también el espacio es respectivo (cosas espaciosas, —ver SE. 436-)

De aquí la falsedad de estas tres sustantivaciones:

- La conciencia de Descartes

- Espacio-tiempo: Newton-Kant

- El ser: Hegel

Realidad-mundo-ser: estructura de lo transcendental.

Despejado el horizonte conceptual del orden transcendental, ya sólo queda determinar en él a la esencia:

Lo transcendental es un carácter y una estructura de lo real en cuanto real (ver SE. 455). La aprehensión transcendental de la esencia hay que seguirla en dos pasos:

8. SU CARÁCTER TRASCENDENTAL. La función propia de la esencia, constituir 'físicamente':

"Esta función talitativa estructurante es una verdadera función, porque talidad no es sinónimo de determinación categorial, sino aquel carácter constructo según el cual cada nota es 'nota-de'." (SE 456)

El 'de suyo' es el carácter transcendental de todo contenido determinado.. El momento de formalidad de realidad es el momento transcendental de las cosas. Así es igual realidad simpliciter a 'de suyo', y la esencia en determinación transcendental es lo simpliciter de la realidad como tal. Esencia = Realidad (ver SE 458) 
Si consideramos a la talidad como una determinación, entonces esencia y realidad es lo mismo. Si distinguimos determinación y talidad, la esencia es momento de la sustantividad:

Identidad de esencia y realidad significa que ambos conceptos expresan pura y simplemente el 'de suyo' de algo. Este 'de suyo' es un mero ex se.

- Realidad = la transcendentalidad misma

- Esencia = el quid real, el contenido determinado de la cosa misma en función transcendental.

En el sentir las cosas mismas como reales, las cosas se muestran alterándose... lo que es 'de suyo', deja de serlo para dar paso a otras cosas 'de suyo', es la caducidad de lo real (ver SE.463).

La limitación pertenece intrínsecamente al 'de suyo' mismo. En un aspecto meramente conceptual, hay una consideración en base a esta limitación.

Son los reductos conceptivos de la esencia, el aspecto meramente 'rato' que corresponde a la "talidad concebida trascendentalmente en cuanto limitada. Pero la esencia independientemente de esta consideración es 'de suyo', de ahí es 'más' que el mero rato. Al ser una 'reducción', lo que realmente tenemos es un 'oquedad'. $Y$ este segundo aspecto conceptivo es la esencia como algo 'meramente existente'". (SE 465).

Bien, en realidad esta disquisición de Zubiri, a propósito de la clásica conceptualización de la esencia y la existencia, la consigno aquí en otra dirección: desde una inteligencia sentiente, la realidad 'se repliega sobre si misma', ese repliegue es apertura, y esta apertura en impresión de realidad (formalidad de...), es excedencia, respectividad, mundo. Qué sea el contenido de la nota o notas esenciales constitutivas de la esencia de algo, es cuestión abierta y ello es el saber de la razón sentiente, pero visto por la 'cara', la de la realidad en la impresión, captamos más que la reducción de la oquedad, captamos el 'prius' sentido que como tal es 'de suyo', que es unidad, suficiencia en orden a... el momento del hacia.

No hay más realidad esenciada que la cosa en su intrínseca constructividad. El constructo transcendental es el que confiere realidad a todas y cada una de las notas. Las notas son actualidad actualizada, esenciada. La manera cómo concretamente las cosas son 'de suyo' es por constructividad.

Respecto de las notas fundadas, su unidad es de ad-herencia (en direcciónhacia). La adherencia es un carácter metafísico de la realidad, su fundamento es la coherencia. Todo lo inesencial está 'reificado' por la esencia como res. (ver SE 480) 


\section{La Esencia: Su Estructura Transcendental.}

El orden transcendental está determinado por el orden de talidad en función transcendental. Lo real, el 'de suyo' es constructividad, y por ser constructo está internamente y trascendentalmente estructurado. (ver SE 481)

La respectividad interna transcendental de lo real, de la esencia en y por sí misma, tiene tres momentos. Son los momentos estructurales del 'de suyo':

Constitución: la unidad transcendental es ante todo una unidad que consiste en ser 'suyo'. Esencia es constitución transcendental. La esencia, lo real, lo 'de suyo' tiene un momento estructural propio: es trascendentalmente constitución con carácter de individuo. (ver SE 491)

Dimensionalidad: (viene del análisis de la verdad real). La actualización de lo real en las notas de la realidad: la presencia de la unidad 'en' las notas. Este respecto proyectivo es la dimensión: en-intus-interioridad (de sí mismo, no confundir con intimidad)-sistematismo... - la interioridad sida (la esencia), esto es un extra, exterioridad: interioridad plasmada-

Trascendentalmente, la esencia como realidad simpliciter es interioridad y exterioridad como momentos de ese constructo metafísico que es el 'de suyo'. (ver SE 493)

El respecto mismo del ex, es la dimensión: es el in en el ex cumo momento del 'de suyo', o en el constructo de realidad.

La dimensionalidad talitativa de la cosa se actualiza en los respectos: de riqueza, solidez y estar siendo. Y tiene una función transcendental muy determinada: mensurar el grado de realidad. Así la riqueza en función transcendental mensura la perfección de lo real qua real. La solidez, mensura la estabilidad. El estar siendo, la duración.(ver SE 498)

Tipicidad: diversidad talitativa en orden a una diferente función transcendental. Esta diferencia es la 'tipicidad' transcendental. Trátase de una diferencia en el constructo metafísico qua metafísico.(ver SE 499)

Esencias cuya función transcendental es instaurar en la realidad 'nada más': transcendentalmente 'cerrada'; algo en sí misma, se agota en 'de suyo en sí'.

Trascendentalmente 'abierta': en su modo de ser 'en sí' son abiertas a toda realidad qua realidad (inteligentes y volentes).(ver SE 500)

Para entender en su verdadera perspectiva la Trilogía sobre la Inteligencia, creo que hay que pensar muy despacio esta cita de Sobre la Esencia:

"La esencia talitativamente intelectiva en función transcendental instaura esa esencia ante todo como algo real, como algo que 'de suyo' es algo 'en sí', pero a una con ello, la instaura como algo trascendentalmente abierto a lo que ella — la esencia intelectiva - no es en sí, o a su propio ser en sí.. Estos 
dos momentos no son estructuralmente independientes, y en su mutua pertenencia transcendental consiste formalmente el tipo de constructo metafísico a que estamos aludiendo. En esto se funda la 'conveniencia' con todo lo real qua real, y por consiguiente el verum y el bonum. Por esta conveniencia la función transcendental de la inteligencia excede a la mera instauración de la inteligencia como realidad propia. Pero este 'exceder', es decir, la 'conveniencia' no es algo primario, sino que es la consecuencia de una estructura transcendental de la esencia intelectiva: la apertura transcendental." (SE 502)

Esta esencia intelectiva se pertenece a sí misma de un modo peculiar: poseerse, que en su acto segundo es justo la vida. Y como carácter del acto primero, es la persona, y como tal tiene personalidad. Ahora bien, el entender la apertura de esta esencia, es entender todo el problema de Inteligencia y Realidad, en lo que a la tal ' $y$ ' se refiere:

Pero antes de sacar conclusiones sobre nuestro estudio, vamos a terminar de extraer de "Sobre la Esencia", eso que Zubiri llama el carácter principial de la Esencia.

Trátase de la principialidad metafísica en cuanto tal. (ver SE 509)

La realidad como principio de lo real puede considerarse en tres direcciones que según se insista más en una que en otra, así será el desarrollo determinado del Pensamiento:

— La realidad de lo real como poder

- La realidad de lo real como fuerza

— La realidad de lo real como nuda realidad (de suyo)

Las notas constitucionales constituyen la sustantividad completa de lo real. Aquello de que es principio la esencia, es pues de la sustantividad.(ver SE 511)

La esencia es determinante 'posicional' o 'funcional'. Así en un constructo, su carácter formal es 'e-structura', el 'efecto' de una estructura es 'posición'. (ver SE 512)

"La estructura es una unidad intrínseca expresada en propiedades sistemáticas." (SE 513)

Respecto de las notas adventicias, la esencia prefija el ámbito de ellas:

"La esencia como estructura es principio de estas notas en cuanto prefija constitutivamente el ámbito de estas conexiones activas o pasivas de una realidad con las demás... (SE 514)... ¿cómo?...en cuanto prefijadas, estas notas... son 'posibles', precisamente porque lo único que la esencia prefija es el ámbito de ellas." (SE. 515) 
Acepta para las esencias cerradas (en si), la conceptualización desde la dynamis griega. Potencia (activa o pasiva): movimiento-hecho.

Pero la esencia abierta sentientemente: el hombre en virtud de su apertura, entre las potencias de 'en sí', modifica este en sí, interponiendo el esbozo de sus 'posibilidades'. Con unas mismas potencias, distintas posibilidades. Las posibilidades pasan al acto por 'aceptación' o ‘aprobación'. De aqui que la actualización sea no un mero movimiento, ni lá actualidad hecho, sino la actualización es un suceder y la actualidad o nota actualizada, suceso o evento.(ver SE 516)

La posibilidad es así una modificación de la potencialidad.

"Tomando a una la constructividad talitativa y la constructividad transcendental, diremos que 'pura naturalidad-eventualidad' es una diferencia metafisica determinada por la diferencia estructural de la esencia. En definitiva, como principio, la esencia es principio estructural de la sustantividad." (SE. 517)

Al final de la Trilogía sobre la Inteligencia dice Zubiri que el gran problema humano es saber estar en la realidad. La ' $y$ ' de Inteligencia y Realidad es el 'estado', que como momento de la realidad es su principio estructural, y como momento de la inteligencia, es también el principio de su estructura sustantiva: la apertura.

\section{Notas}

1. (Profesor de Metafísica Univ.Comillas-Madrid) UCA-San Salvador, julio, 2000

2. NHD: Naturaleza Historia Dios. X.Zubiri. Alianza Editorial, $\left(5^{\circ} \mathrm{cd} .1985\right)$

3. Hay que dejar por sentado que el concepto de respectividad madura muy tardiamente en Zubiri .(De momento me remito al trabajo de Antonio Gonzálcz: 'La idca de mundo en la filosofía de Zubiri. Miscclánca Comillas, 44 (1986), pp.485-521, dondc desarrolla de una forma cxhaustiva csta cucstión). Pucde vcrsc lambićn la Introducción a mi libro: Enfrentamicnto y Actualidad, Comillas-Madrid, 1999.

4. Aquí aparcec la respectividad como ambivalentc a cosmos y mundo, pero no sc olvide cl contcxto: la gencración.

5. Para esta cucstión pucde verse mi libro, Enfrentamicnto y Actualidad. Comillas-Madrid, 1999

6. Para cl desarrollo y matización de estos aspectos cs fundamental el cstudio de Juan Bañon: Metafisica y Neología en Zubiri. Publicaciones de la Universidad Pontificia de Salamanca, 1999. 